\title{
Over-Production, Crystallization, and Preliminary X-ray Crystallographic Analysis of a Coiled-Coil Region in Human Pericentrin
}

\author{
Min Ye Kim, Jeong Kuk Park, Yeowon Sim, Doheum Kim, Jeong Yeon Sim and SangYoun Park * \\ School of Systems Biomedical Science, Soongsil University, Seoul 06978, Korea; abpmrrc@nate.com (M.Y.K.); \\ water1028@naver.com (J.K.P.); rato0001@naver.com (Y.S.); dohuemi@naver.com (D.K.); \\ sjyeon1103@naver.com (J.Y.S.) \\ * Correspondence: psy@ssu.ac.kr; Tel.: +82-2-820-0456 \\ Academic Editor: Jolanta Prywer \\ Received: 12 September 2017; Accepted: 28 September 2017; Published: 2 October 2017
}

\begin{abstract}
The genes encoding three coiled-coil regions in human pericentrin were gene synthesized with Escherichia coli codon-optimization, and the proteins were successfully over-produced in large quantities using E. coli expression. After verifying that the purified proteins were mostly composed of $\alpha$-helices, one of the proteins was crystallized using polyethylene glycol 8000 as crystallizing agent. X-ray diffraction data were collected to $3.8 \AA$ resolution under cryo-condition using synchrotron X-ray. The crystal belonged to space group $C 2$ with unit cell parameters $a=324.9 \AA, b=35.7 \AA$, $c=79.5 \AA$, and $\beta=101.6^{\circ}$. According to Matthews' coefficient, the asymmetric unit may contain up to 12 subunits of the monomeric protein, with a crystal volume per protein mass $\left(\mathrm{V}_{\mathrm{M}}\right)$ of $1.96 \AA^{3} \mathrm{Da}^{-1}$ and a $37.3 \%$ solvent content.
\end{abstract}

Keywords: pericentrin; coiled-coil; centrosome; pericentriolar material (PCM)

\section{Introduction}

The centrosome is the main microtubule organizing center (MTOC) in animal cells. In non-mitotic interphase cells, the centrosome is located near the nucleus to produce an assembly of microtubules that radiates towards the cell periphery, serving as tracks for motor protein-mediated transport of cellular compartments. During mitosis, microtubules reorganize from the centrosomes to form spindle poles that accurately segregate the duplicated chromosomes in two. The centrosome consists of a pair of orthogonally arranged centrioles surrounded by pericentriolar material (PCM). The PCM includes factors such as the $\gamma$-tubulin ring complex ( $\gamma$-TuRC) that directly function to nucleate the microtubule arrays [1-4]. Pericentrin (PCNT) is a large $\sim 360 \mathrm{kDa}$ protein that also exists within PCM [5] to act as a scaffold for anchoring multiple proteins of the PCM [6]. PCNT contains a series of predicted coiled-coil regions over most of their length [5], but a highly conserved PCM targeting motif called the PACT domain is found near the C-terminus [7] (Figure 1). PCNT has been linked to many human disorders [6], and one of them is the loss-of-function mutations that cause microcephalic osteodysplastic primordial dwarfism type II (MOPD II) [8].

In this study, three regions in the human PCNT which are predicted as coiled-coils were successfully over-produced in Escherichia coli using plasmids containing E. coli codon-optimized PCNT gene. The high $\alpha$-helical contents for the three PCNT proteins were further confirmed by circular dichroism analysis, and one of them was crystallized for preliminary X-ray crystallographic analysis. 


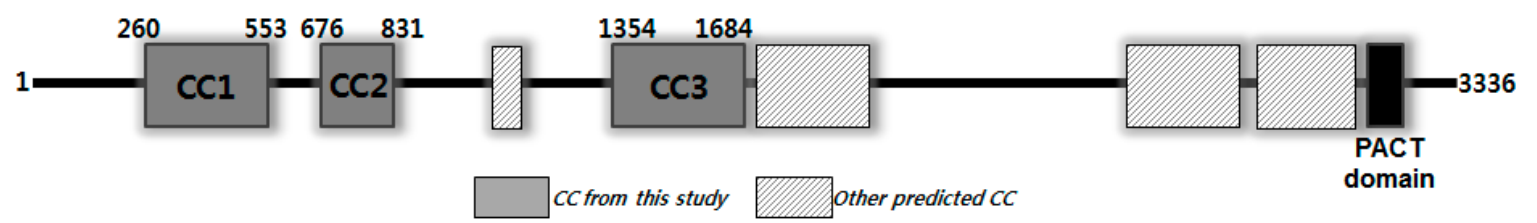

Human PCNT

Figure 1. Regions of human pericentrin (PCNT) showing predicted coiled-coil (CC) and the PACT domain.

\section{Materials and Methods}

\subsection{Macromolecule Production}

The DNA encoding three regions in human pericentrin (PCNT, full length of residues 1-3336) which are predicted to encode coiled-coil (CC) motifs (CC1, 260-553; CC2, 676-831; CC3, 1354-1684) were synthesized with an addition of nucleotides encoding N-terminal His-tag (Bioneer, Daejeon, Korea) for affinity purification. All genes were codon-optimized for expression in E. coli and cloned into pET28a vector (Merck, Kenilworth, NJ, USA) using NdeI and BamHI restriction enzyme sites. The generated plasmids were all sequence verified of the insert region, and were used to transform the E. coli BL21 (DE3) (Merck, Kenilworth, NJ, USA) cells using heat shock at $42{ }^{\circ} \mathrm{C}(45 \mathrm{~s})$. The transformed cells were grown at $37{ }^{\circ} \mathrm{C}$ in $1 \mathrm{~L}$ of Luria-Bertani (LB) medium to an $\mathrm{OD}_{600}$ of $\sim 0.8$ in the presence of $25 \mu \mathrm{g} / \mathrm{mL}$ kanamycin. Expression of the recombinant protein was induced by the addition of $0.5 \mathrm{mM}$ isopropyl-D-thiogalactopyranoside (IPTG) at $22^{\circ} \mathrm{C}$, and cells were allowed to grow for an extra $16 \mathrm{~h}$. Cells were harvested using centrifugation at $4500 \times \mathrm{g}$ for $10 \mathrm{~min}\left(4^{\circ} \mathrm{C}\right)$. All three N-terminal $\mathrm{His}_{6}$-tagged proteins of PCNT were over-produced with soluble expression of the proteins. For protein purification, the bacterial cell pellets were re-suspended in $50 \mathrm{~mL}$ ice-cold lysis buffer (20 mM Tris pH 7.5, $500 \mathrm{mM} \mathrm{NaCl}$, and $5 \mathrm{mM}$ imidazole) and lysed on ice by sonication. The homogenates were centrifuged at $70,000 \times \mathrm{g}$ for $30 \mathrm{~min}\left(4^{\circ} \mathrm{C}\right)$, and supernatants poured over a $5 \mathrm{~mL}$ Ni-nitrilotriacetic acid agarose (Ni-NTA) (Qiagen, Hilden, Germany) gravity column. The columns were washed with five column volumes of wash buffer $(20 \mathrm{mM}$ Tris pH 7.5, $20 \mathrm{mM}$ imidazole, and $500 \mathrm{mM} \mathrm{NaCl}$ ), and the proteins were eluted with elution buffer (20 mM Tris pH 7.5, $200 \mathrm{mM}$ imidazole, and $500 \mathrm{mM} \mathrm{NaCl}$ ). The elution fractions containing the PCNT proteins were checked using Bradford assay (BioRad, Berkeley, CA, USA), combined, and added with $50 \mu \mathrm{L}$ of $0.25 \mathrm{U} / \mu \mathrm{L}$ bovine thrombin (Invitrogen, Carlsbad, CA, USA). After proteolysis of the $\mathrm{His}_{6}$-tag for $16 \mathrm{~h}$ incubation at $4{ }^{\circ} \mathrm{C}$, the protein samples were further purified using a HiLoad ${ }^{\circledR}$ 26/60 Superdex ${ }^{\circledR} 200$ size-exclusion column (SEC) pre-equilibrated with SEC buffer (50 mM Tris pH 7.5, $150 \mathrm{mM} \mathrm{NaCl}$, and $2 \mathrm{mM}$ DTT). The proteolysis mixes were loaded into the column connected to an ÄKTA FPLC system (GE Healthcare, Little Chalfont, UK). The elution profiles of all three proteins showed one major peak (Figure 2), and the fractions were concentrated by Amicon ${ }^{\circledR}$ ultracentrifugation filters (Merck). Final protein concentrations were estimated by $\mathrm{A}_{280}$ with a molar extinction coefficient $\left(\mathrm{CC} 1,15220 \mathrm{M}^{-1} \mathrm{~cm}^{-1}\right.$; CC2, $6970 \mathrm{M}^{-1} \mathrm{~cm}^{-1}$; CC3, $11380 \mathrm{M}^{-1} \mathrm{~cm}^{-1}$ ) calculated based upon the numbers of tryptophan and tyrosine residues [9]. Purity and homogeneity were assessed using SDS-PAGE analysis (Figure 2). The concentrated proteins in SEC buffer were flash-cooled and stored in liquid nitrogen. 


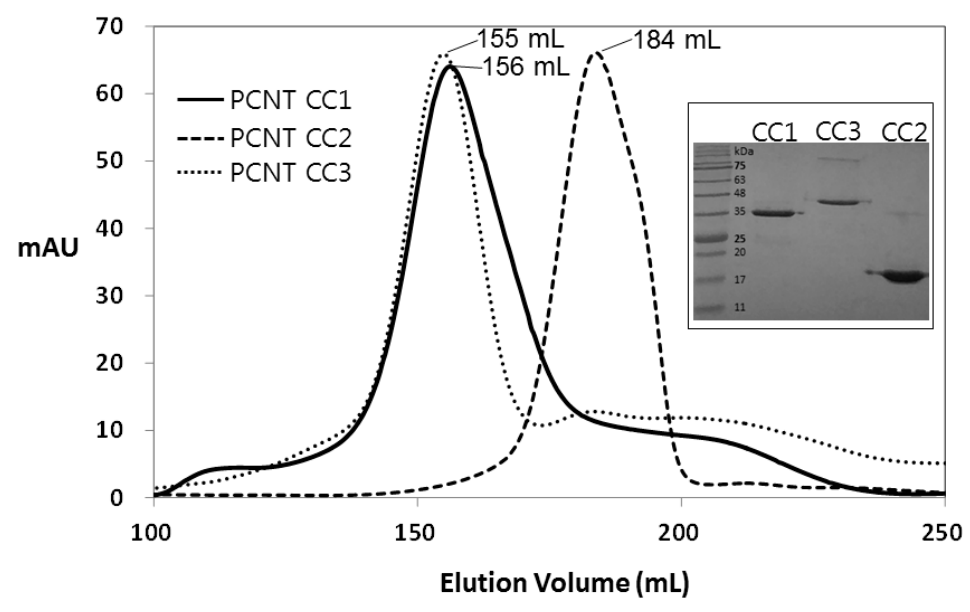

Figure 2. Size-exclusion chromatograms of three PCNT coiled-coil proteins (CC1, CC2, and CC3) and SDS-PAGE analysis of the concentrated fractions under the elution peaks (inset).

\subsection{Circular Dichroism (CD) Studies for Secondary Structure Estimation}

The contents of the secondary structure elements in the expressed PCNT proteins were estimated by scanning ellipticity over wavelength (200-240 nm) using a JASCO spectropolarimeter (Model J-810, Tokyo, Japan). The three PCNT proteins with the final concentration of $0.3 \mu \mathrm{g} / \mathrm{mL}$ were analyzed using a $0.1 \mathrm{~cm}$ path-length cuvette to obtain the spectra. Secondary structure estimation programs of K2D2 [10] and K2D3 [11] were applied to the CD data for approximation of the secondary structure content. Because the fitting of CD data for secondary structure contents are highly dependent on the exact concentration of the protein (which in our case was estimated from calculated molar extinction coefficient), up to two-fold differences in the protein concentrations were allowed during the fits.

\subsection{Crystallization}

Although all three PCNT proteins were screened using commercial Wizard ${ }^{\circledR}$ solutions (Molecular Dimensions) for conditions to obtain crystals, only crystals of PCNT CC2 were obtained (Table 1). The crystal drops were set by mixing equal $1 \mu \mathrm{L}$ volumes of the reservoir solution $(10 \%(w / v)$ PEG $8 \mathrm{~K}$ $100 \mathrm{mM}$ potassium phosphate monobasic/sodium phosphate dibasic $\mathrm{pH} 6.2$, and $200 \mathrm{mM} \mathrm{NaCl}$ ) and the PCNT CC2 concentrate $(60 \mathrm{mg} / \mathrm{mL})$ in SEC buffer, and were equilibrated against $500 \mu \mathrm{L}$ of the reservoir solution. Several crystals were harvested, gel-electrophoresed, and their tryptic digestion fragments were analyzed using LC-MS/MS (Table 2). The crystals were transferred to a cryo-protectant solution of $30 \%$ glycerol supplemented to the reservoir solution, flash-cooled in liquid nitrogen for storage, and transported to a synchrotron facility for diffraction experiment.

Table 1. Macromolecule production information for PCNT CC2.

\begin{tabular}{cc}
\hline Source Organism & Homo Sapiens \\
\hline DNA source & Synthesized DNA \\
Cloning sites & NdeI and BamHI \\
Cloning vector & pET28a \\
Expression vector & pET28a \\
Expression host & E. coli BL21 (DE3) \\
& MGSSHHHHHHSSGLVPRGSHM- $^{676}$ EHKVQ $^{680}$ \\
& ${ }^{681}$ LSLLQTELKEEIELLKIENRNLYGKLQHET $^{710}$ \\
Complete amino acid sequence of the & ${ }^{711}$ RLKDDLEKVKHNLIEDHQKELNNAKQKTEL $^{740}$ \\
construct produced ${ }^{1}$ & ${ }^{741}$ MKQEFQRKETDWKVMKEELQREAEEKLTLM $^{770}$ \\
& ${ }^{771}$ LLELREKAESEKQTIINKFELREAEMRQLQ $^{800}$ \\
& ${ }^{801}$ DQQAAQILDLERSLTEQQGRLQQLEQDLTSD \\
\end{tabular}

${ }^{1}$ Non-native His $_{6}$-tag and thrombin site are underlined. 
Table 2. List of peptide fragments found from mass spectrometry analysis of the crystallized PCNT CC2.

\begin{tabular}{|c|c|}
\hline Peptide Sequence $^{1}$ & $\mathrm{MH}^{+}(\mathrm{Da})$ \\
\hline GSHM- $^{676}$ EHKVQLSLLQTELKEEIELLK $^{696}$ & 2932.59 \\
\hline${ }^{679}$ VQLSLLQTELKEEIELLKIENR ${ }^{700}$ & 2638.52 \\
\hline${ }^{678}$ KVQLSLLQTELKEEIELLK ${ }^{696}$ & 2254.33 \\
\hline${ }^{683}$ LLQTELKEEIELLKIENR $^{700}$ & 2211.26 \\
\hline${ }^{676}{ }^{6 H K V Q L S L L Q T E L K E E I E L L K ~}{ }^{696}$ & 2520.44 \\
\hline${ }^{682}$ SLLQTELKEEIELLKIENR ${ }^{700}$ & 2298.30 \\
\hline${ }^{681}$ LSLLQTELKEEIELLKIENR ${ }^{700}$ & 2411.38 \\
\hline${ }^{793}$ EAEMRQLQDQQAAQILDLER $^{812}$ & 2385.19 \\
\hline${ }^{684}$ LQTELKEEIELLKIENR $^{700}$ & 2098.18 \\
\hline${ }^{679}$ VQLSLLQTELKEEIELLK $^{696}$ & 2126.23 \\
\hline 682SLLQTELKEEIELLK ${ }^{696}$ & 1786.02 \\
\hline${ }^{685}{ }^{\circ T E L K E E I E L L K I E N R ~}{ }^{700}$ & 1985.09 \\
\hline${ }^{681}$ LSLLQTELKEEIELLK $^{696}$ & 1899.11 \\
\hline${ }^{683}$ LLQTELKEEIELLK $^{696}$ & 1698.99 \\
\hline${ }^{721}$ HNLIEDHQKELNNAK $^{735}$ & 1802.92 \\
\hline${ }^{686}$ TELKEEIELLKIENR ${ }^{700}$ & 1857.03 \\
\hline${ }^{685}$ QTELKEEIELLK ${ }^{696}$ & 1472.82 \\
\hline${ }^{719}$ VKHNLIEDHQKELNNAK $^{735}$ & 2030.08 \\
\hline${ }^{684}$ LQTELKEEIELLK $^{696}$ & 1585.91 \\
\hline${ }^{778}$ AESEKQTIINKFELR ${ }^{792}$ & 1805.98 \\
\hline${ }^{798}{ }^{Q L Q D Q Q A A Q I L D L E R}{ }^{812}$ & 1768.92 \\
\hline${ }^{687}$ ELKEEIELLKIENR $^{700}$ & 1755.99 \\
\hline${ }^{767}$ LTLMLLELREKAESEK $^{782}$ & 1903.06 \\
\hline${ }^{688}$ LKEEIELLKIENR $^{700}$ & 1626.95 \\
\hline${ }^{798}$ QLQDQQAAQILDLERSLTEQQGR $^{820}$ & 2668.37 \\
\hline${ }^{757}$ EELQREAEEKLTLMLLELR ${ }^{775}$ & 2343.26 \\
\hline${ }^{762}$ EAEEKLTLMLLELR 775 & 1687.93 \\
\hline${ }^{762}{ }^{E A E E K L T L M L L E L R E K ~}{ }^{777}$ & 1945.07 \\
\hline
\end{tabular}

${ }^{1}$ Peptide hits are listed based on the sorted cross correlation score (XCorr) starting from 5.0 to 10.8 [XCorr is defined by Proteome Discoverer 1.3 (Thermo Scientific, USA)].

\subsection{Data Collection and Processing}

X-ray diffraction data were collected at $100 \mathrm{~K}$ using a CCD detector (ADSC Quantum 315r) at beamline $5 \mathrm{C}$ of the Pohang Light Source (PLS, Pohang, Korea). The crystal was rotated through a total of $180^{\circ}$ with $1.0^{\circ}$ oscillation range per frame. Data were processed in space group $\mathrm{C} 2$ using HKL2000 [12] (Table 3).

Table 3. Data collection and processing.

\begin{tabular}{cc}
\hline Diffraction Source & Pohang Light Source (PLS 5C) (Pohang, Korea) \\
\hline Wavelength $(\AA)$ & 0.9795 \\
Temperature $(\mathrm{K})$ & 100 \\
Detector & ADSC Quantum $315 \mathrm{r}$ \\
Crystal-detector distance $(\mathrm{mm})$ & 450 \\
Rotation range per image $\left({ }^{\circ}\right)$ & 1 \\
Total rotation range $\left({ }^{\circ}\right)$ & 180 \\
Exposure time per image $(\mathrm{s})$ & 1 \\
Space group & $\mathrm{C} 2$ \\
$a, b, c(\AA)$ & $324.9,35.7,79.5$ \\
$\alpha, \beta, \gamma\left({ }^{\circ}\right)$ & $90.0,101.6,90.0$ \\
Mosaicity $\left({ }^{\circ}\right)$ & 1.1 \\
Resolution range $(\AA)$ & $50.0-3.80(3.87-3.80)^{1}$ \\
Total No. of reflections & 16,221 \\
No. of unique reflections & 9074 \\
Completeness $(\%)$ & $97.3(89.7)$ \\
Redundancy & $1.7(1.6)$ \\
$\langle I / \sigma(I)\rangle$ & $18.1(3.9)$ \\
$R_{\text {merge }}$ & $0.463(0.120)$ \\
$R_{\text {p.i.m. }}$ & $0.081(0.303)$ \\
CC $1 / 2$ & $(0.918)$ \\
Overall $B$ factor from Wilson plot $\left(\AA^{\circ}\right)$ & 78.7 \\
\hline
\end{tabular}

${ }^{1}$ Values for the outer shell are given in parentheses. 


\section{Results and Discussion}

Various coiled-coil prediction algorithms such as COILS [13] suggest multiple occurrences of coiled-coil regions in the large-sized (3336 amino acids) human PCNT (Figure 1). Three human PCNT constructs of three coiled-coil regions were generated by gene synthesis with $E$. coli codon-optimization for bacterial recombinant expression. The proteins were successfully over-produced in E. coli as a soluble protein and purified with an overall yield of $>50 \mathrm{mg}$ per $1 \mathrm{~L}$ of LB culture. The SEC elution profiles of the three coiled-coil regions on HiLoad ${ }^{\circledR} 26 / 60$ Superdex ${ }^{\circledR} 200$ showed a single major peak, and SDS-PAGE analysis of the concentrated proteins under the peaks indicated successful expression of the proteins (Figure 2). The estimated molecular masses of the proteins based on SDS-PAGE standard protein markers were $\sim 35 \mathrm{kDa}(\mathrm{CC} 1), \sim 17 \mathrm{kDa}(\mathrm{CC} 2)$, and $\sim 40 \mathrm{kDa}(\mathrm{CC} 3)$, which were as expected from the calculated molecular masses of the protein (CC1, 35.5 kDa; CC2, 19.2 kDa; CC3, 38.7 kDa).

Predicted to form mostly coiled-coils, the secondary structure contents of PCNT were expected to be largely $\alpha$-helical. Circular dichroism (CD) analyses of the purified PCNTs confirmed this prediction (Figure $3 \mathrm{a}-\mathrm{c}$ ). When the experimental ellipticity values determined at different wavelengths (200-240 nm) were used for secondary structure estimations, the results indicated that large parts of the proteins were mostly $\alpha$-helical with $<5 \%$ being $\beta$-strand (Figure 3 ). For instance, PCNT CC1 was estimated with 69\% (K2D2) or 81\% (K2D3) $\alpha$-helicity. Additionally, PCNT CC2 was estimated with 76\% (K2D2) or 89\% (K2D3) $\alpha$-helicity, and PCNT CC3 with 63\% (K2D2) or 67\% (K2D3) $\alpha$-helicity. Hence, the overall trend indicated that the three PCNT proteins were made up largely of $\alpha$-helices as predicted from the amino acid sequences.

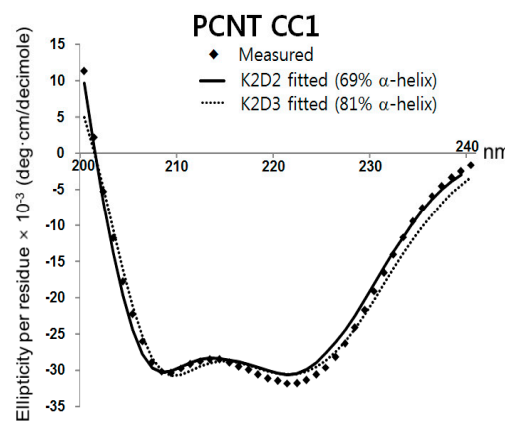

(a)

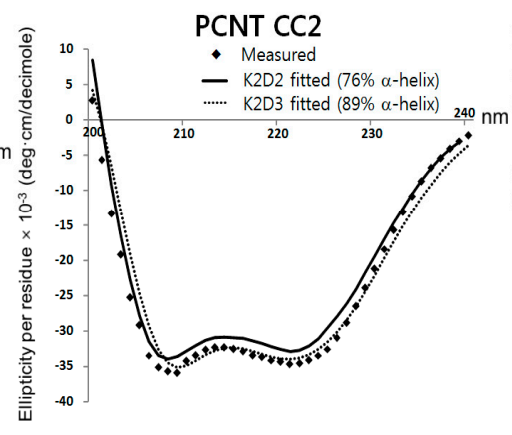

(b)

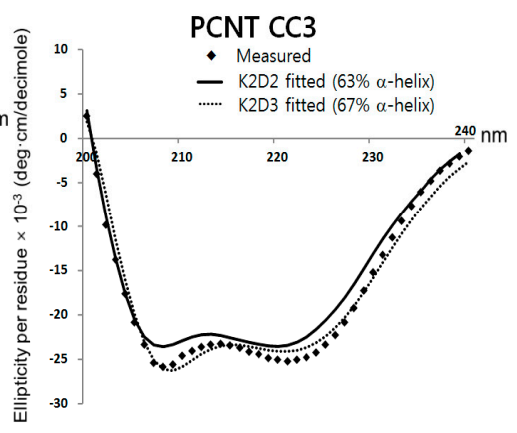

(c)

Figure 3. Circular dichroism studies for the estimation of secondary structure elements in PCNT (a) CC1, (b) CC2, and (c) CC3.

Among the three purified PCNT proteins, crystals were obtained only from PCNT CC2. Clustered crystals were grown against a reservoir solution of $10 \%(w / v)$ PEG $8 \mathrm{~K}, 100 \mathrm{mM}$ potassium phosphate monobasic/sodium phosphate dibasic $\mathrm{pH} 6.2$, and $200 \mathrm{mM} \mathrm{NaCl}$ at $4{ }^{\circ} \mathrm{C}$. Within two days, the crystals grew to approximately $5 \mu \mathrm{m} \times 50 \mu \mathrm{m} \times 100 \mu \mathrm{m}$ (Figure 4), which was sufficient in size for X-ray diffraction experiments. The mass spectrometry analysis on the tryptic digestion fragments of the crystals confirmed the content of PCNT CC2 (Figure 4 and Table 2). The peptides found were mapped into the expressed PCNT CC2 protein sequence, resulting in 99.4\% sequence coverage. Most crystals screened for X-ray diffraction using synchrotron radiation showed anisotropic diffraction. However, one out of ten crystals tested gave isotropic diffraction in all directions of oscillation to an average resolution limit of $3.8 \AA$ (Figure 5). Alterations in PEG $8 \mathrm{~K}$ concentrations, $\mathrm{pH}$, as well as trials of different types of PEGs as the crystallization agent did not affect the overall diffraction quality. A total of 9074 unique reflections were measured and merged in the space group $C 2$ (unit cell parameters of $\mathrm{a}=324.9 \AA, \mathrm{b}=35.7 \AA, \mathrm{c}=79.5 \AA$, and $\left.\beta=101.6^{\circ}\right)$. The merged dataset was overall $97.3 \%$ complete with $R_{\text {merge }}$ of $12 \%$ and $R_{\text {p.i.m. }}$ of $8.1 \%$ (50-3.80 $\AA$ ). The statistics for the collected data are summarized in Table 3. According to the Matthews coefficient [14], the asymmetric unit may contain up to 12 
subunits of the monomeric PCNT CC2 with a crystal volume per protein mass ( $\left.V_{M}\right)$ of $1.96 \AA^{3} \mathrm{Da}^{-1}$ and $37.3 \%$ solvent content. An asymmetric unit containing eight subunits is also plausible with $V_{M}$ of $2.93 \AA^{3} \mathrm{Da}^{-1}$ and $58.2 \%$ solvent content. A self-rotation function (kappa section $=180^{\circ}$ ) revealed a peak corresponding to two-fold noncrystallographic symmetry, further suggesting that PCNT CC2 exists as a dimer in the crystal. Because no model for PCNT exists in the Protein Databank (PDB), attempts for phasing via molecular replacement could not be made.

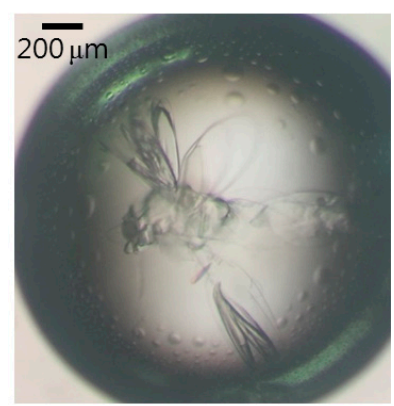

(a)

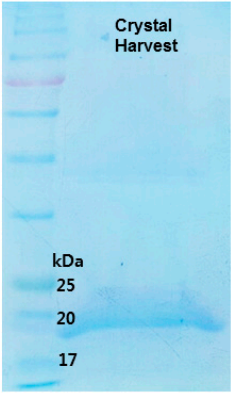

(b)

Figure 4. (a) Clustered crystals of PCNT CC2 and (b) the SDS-PAGE analysis of harvested crystals used for MS analysis of tryptic digestion fragments.

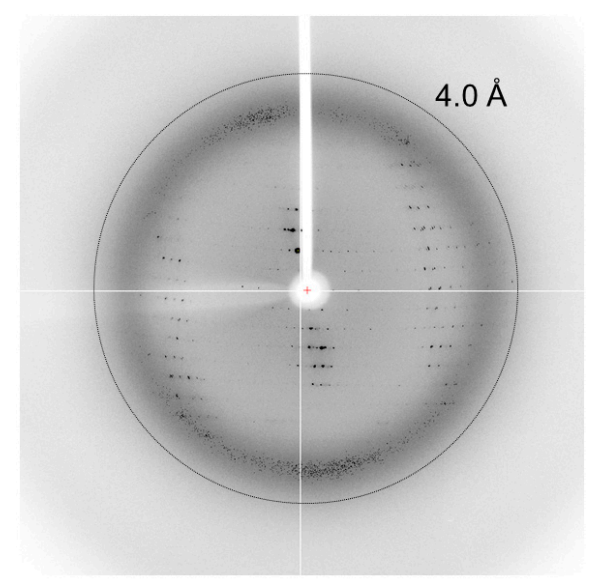

Figure 5. Representative diffraction image of the PCNT CC2 crystal.

In the future, we plan to determine the high-resolution structure of the coiled-coil PCNT CC2 by improving the current $3.8 \AA$ resolution crystal and also by direct phasing. Since no information on the structure of PCNT exists, the structure would give insight towards understanding the mechanism that governs the function of PCNT.

Acknowledgments: The authors would like to thank the staff at PAL 5C beamline for their support and beam time. This research was supported by the Basic Science Program through the National Research Foundation of Korea (NRF) funded by the Ministry of Science, ICT \& Future Planning (2016R1D1A1A09918187).

Author Contributions: Min Ye Kim and SangYoun Park conceived and designed the experiments; Min Ye Kim and Jeong Kuk Park performed the experiments; Jeong Kuk Park, Yeowon Sim, Doheum Kim and Jeong Yeon Sim analyzed the data; Sang Youn Park wrote the paper.

Conflicts of Interest: The authors declare no conflict of interest.

\section{References}

1. Sluder, G. Two-way traffic: Centrosomes and the cell cycle. Nat. Rev. Mol. Cell Biol. 2005, 6, 743-748. [CrossRef] [PubMed] 
2. Takahashi, M.; Yamagiwa, A.; Nishimura, T.; Mukai, H.; Ono, Y. Centrosomal proteins CG-NAP and kendrin provide microtubule nucleation sites by anchoring gamma-tubulin ring complex. Mol. Biol. Cell 2002, 13, 3235-3245. [CrossRef] [PubMed]

3. Zimmerman, W.C.; Sillibourne, J.; Rosa, J.; Doxsey, S.J. Mitosis-specific anchoring of gamma tubulin complexes by pericentrin controls spindle organization and mitotic entry. Mol. Biol. Cell 2004, 15, 3642-3657. [CrossRef] [PubMed]

4. Delaval, B.; Doxsey, S.J. Pericentrin in cellular function and disease. J. Cell Biol. 2010, 188, 181-190. [CrossRef] [PubMed]

5. Doxsey, S.; Zimmerman, W.; Mikule, K. Centrosome control of the cell cycle. Trends Cell Biol. 2005, 15, 303-311. [CrossRef] [PubMed]

6. Doxsey, S.J.; Stein, P.; Evans, L.; Calarco, P.D.; Kirschner, M. Pericentrin, a highly conserved centrosome protein involved in microtubule organization. Cell 1994, 76, 639-650. [CrossRef]

7. Gillingham, A.K.; Munro, S. The PACT domain, a conserved centrosomal targeting motif in the coiled-coil proteins AKAP450 and pericentrin. EMBO Rep. 2000, 1, 524-529. [CrossRef] [PubMed]

8. Rauch, A.; Thiel, C.T.; Schindler, D.; Wick, U.; Crow, Y.J.; Ekici, A.B.; van Essen, A.J.; Goecke, T.O.; Al-Gazali, L.; Chrzanowska, K.H.; et al. Mutations in the pericentrin (PCNT) gene cause primordial dwarfism. Science 2008, 319, 816-819. [CrossRef] [PubMed]

9. Gill, S.C.; von Hippel, P.H. Calculation of protein extinction coefficients from amino acid sequence data. Anal. Biochem. 1989, 182, 319-326. [CrossRef]

10. Perez-Iratxeta, C.; Andrade-Navarro, M.A. K2D2: Estimation of protein secondary structure from circular dichroism spectra. BMC Struct. Biol. 2008, 8, 1-5. [CrossRef] [PubMed]

11. Louis-Jeune, C.; Andrade-Navarro, M.A.; Perez-Iratxeta, C. Prediction of protein secondary structure from circular dichroism using theoretically derived spectra. Proteins 2012, 80, 374-381. [CrossRef] [PubMed]

12. Otwinowski, Z.; Minor, W. Processing of X-ray Diffraction Data Collected in Oscillation Mode. Methods Enzymol. 1997, 276, 307-326. [PubMed]

13. Lupas, A.; Van Dyke, M.; Stock, J. Predicting Coiled Coils from Protein Sequences. Science 1991, 252, 1162-1164. [CrossRef] [PubMed]

14. Matthews, B.W. Solvent content of protein crystals. J. Mol. Biol. 1968, 33, 491-497. [CrossRef] 